\title{
JOSÉ ENRIQUE MARTÍNEZ FERNÁNDEZ, FERVOR DE POESÍA
}

\author{
Alfredo SALDAÑA
}

Universidad de Zaragoza

lo largo de mi vida laboral, en ocasiones, me he encontrado con personas que merecen la
pena, seres humanos extraordinariamente generosos que han entendido su trabajo - nuestro
trabajo - como una oportunidad para crecer juntos. Sin ninguna duda, una de esas personas ha sido José Enrique Martínez Fernández, quien desde su casa, la Universidad de León, ha sabido tejer con gran prodigalidad una amplia red de afectos y compromisos que va más allá de la literatura. En el transcurso de estos últimos veinte años, no he conocido a nadie que hable mal de él y, por el contrario, he tenido la oportunidad de encontrarme con mucha gente que solo tiene palabras de afecto, elogio y agradecimiento hacia él, una persona que con coherencia y suma discreción ha desarrollado una trayectoria ejemplar. Desde luego, aunque eso sea algo que solo a él y a mí nos concierne, mi vida en el campo académico ha sido, por su culpa, mucho más fructífera, provechosa y agradable de lo que probablemente hubiera sido sin su presencia. Zaragoza, León, Madrid, Valladolid, Granada, Jaca, La Bañeza, han sido algunos lugares en los que, por diferentes razones y a veces alrededor de unos prietos picudos, mencías o somontanos, hemos compartido encuentros, conversaciones, preocupaciones, proyectos y deseos. En la distancia, solo geográfica, José Enrique ha sido para mí un referente, un modelo de conducta y presencia en el mundo académico.

Más allá o al margen de estas consideraciones, quiero en estas páginas dejar testimonio de cómo algunos trabajos de José Enrique Martínez me han acompañado a lo largo de estos años, aclarándome muchas y muy diversas cuestiones. Podría muy bien ser este el lugar y el momento de glosar su extensa y reveladora producción científica, en la que encontramos un volumen considerable de sugerentes trabajos dedicados al análisis de la poesía, aportaciones que dan muestra de unos firmes y asentados recursos propedéuticos, una solvencia teórica y un conocimiento exhaustivo de la materia textual investigada. Podría, como escribo, ser esta la ocasión, pero, para llevarla a cabo, necesitaría extenderme mucho más de lo aconsejable en una oportunidad como esta. Ahí están, al margen de esos otros ensayos dedicados a diferentes narradores y al trazado de cartografías más o menos generales por las que ha transcurrido la poesía de este tiempo (Martínez Fernández, 1989; 1997; 2005), sus trabajos sobre Cernuda, Leopoldo Panero, Crémer, Ángel González, Gamoneda, Brines, Botas, 
Colinas, Carvajal, José Luis Puerto, etc.; me centraré, pues, en cinco de esos títulos, cinco textos imprescindibles para conocer mejor la realidad compleja y multiforme de la poesía española contemporánea y, lo que es más importante, para apreciar y valorar el alcance y la profundidad del pensamiento poético del propio José Enrique Martínez. Se trata, según el orden cronológico de publicación, de El fragmentarismo poético contemporáneo (1996), La intertextualidad literaria (2001), «Elogio de la poesía» (2002), un texto menor, alguien diría de circunstancias, pero, en mi opinión, clave para entender la permanente, profunda, visceral y al mismo tiempo meditada relación que su autor ha mantenido a lo largo de su vida con la poesía, En la luz respirada (2004), edición de parte de la poesía de Antonio Colinas, y El lienzo de la página (2017), un volumen de reciente aparición que recoge dieciséis textos, casi todos publicados con anterioridad, cuyo vínculo se encuentra en las relaciones que la poesía mantiene con las otras artes.

El fragmentarismo poético contemporáneo (fundamentos teórico-críticos) se centró en su momento en un campo sobre el que apenas había estudios teóricos de envergadura (aunque sí desde la perspectiva de la crítica literaria, centrados en determinadas obras y autores) y supuso un primer y ya concienzudo trabajo de investigación sobre algunas formas y registros expresivos que conllevan un considerable nivel de dificultad, formas y registros por los que tradicionalmente la academia había mostrado un escaso interés. José Enrique Martínez - y este será un rasgo constante a lo largo de toda su trayectoria científica - demuestra un excelente conocimiento de la bibliografía (primaria y secundaria, literaria y teórica), una bibliografía, además, que maneja con una gran competencia y honestidad, citando y revelando en todo momento - cuando es necesario, claro — las fuentes de sus planteamientos. Se analizan en este volumen algunas formas distintivas de la poesía contemporánea surgida con posterioridad a la vanguardia histórica, convenciones en las que se manifiestan ciertas tensiones latentes a partir de las cuales se pueden explicar y por lo tanto comprender determinados fenómenos característicos de la poesía contemporánea, formas que

\footnotetext{
tienen su origen en (y se han desarrollado a partir de) la tensión dialéctica latente en una serie de dualidades (diacrónica y sincrónicamente consideradas) que podemos sintetizar en el par oralidad / escritura y, consiguientemente, en una serie de términos en contraste como escucha / lectura, oído / vista, ritmo marcado o exterior / ritmo mental o interior, ausencia (voz) / presencia (grafía), memoria oral / memoria escrita (a las que podrían añadirse sin resistencia dualidades del tipo tradición / renovación, tradición / creación individual, etc.) (Martínez Fernández, 1996: 13).
}

José Enrique Martínez, en diferentes trabajos, ha demostrado ser un excelente conocedor de esa antiquísima tradición que ha hecho del cultivo de determinadas fórmulas (acrósticos, anagramas, caligramas, emblemas, jeroglíficos, laberintos, etc.) el centro de una producción literaria en la que se somete al ingenio a ciertos grados de dificultad. Así, es evidente que, tal como resalta el propio autor del ensayo, determinados fenómenos - la peculiar disposición tipográfica, generadora de dispersión, el fragmentarismo y la desarticulación o desmembramiento de moldes estróficos canónicos-, vinculados a la crisis de la oralidad y al surgimiento del verso libre, leídos a la luz de dichas tensiones, pueden entenderse en su mayor alcance y comprenderse en su total y compleja diversidad. Experto, asimismo, en la estructura rítmica sobre la que se sustenta la poesía, aunque esa ensambladura no 
constituya en esta ocasión el centro de su trabajo, José Enrique Martínez es muy consciente de que el nexo, el punto fuerte, de la interpretación poética reside «en la tensión latente entre el primitivo carácter oral de la poesía y su destino actual, la lectura» (1996: 15).

La intertextualidad literaria (Base teórica y práctica textual) continúa siendo todavía hoy, dieciséis años después de su publicación, uno de los mejores y más completos análisis sobre los intertextos perceptibles en la poesía en español (en el libro se estudian también textos de autores hispanoamericanos) posterior a 1939. Una vez más, igualmente en esta oportunidad J. E. Martínez demuestra ser un lector penetrante y un intérprete muy bien informado de la poesía contemporánea, en la que observa «su intensa intertextualidad, explícita o difusa, que integra en el tejido textual voces otras que hacen del texto un cuerpo abierto, taracea a veces de una abundante copia de citas y ecos» (Martínez Fernández, 2001: 9). El desafío, en este caso, no era pequeño, pues, como es sabido, ese concepto, la intertextualidad, se ha convertido en una cuestión disputada central en el pensamiento literario de estas últimas décadas, desde que Julia Kristeva lo pusiera en circulación en 1967 al escribir un artículo sobre el pensamiento literario de Bajtín publicado en Critique. Así, nos encontramos con un trabajo en el que su autor sale mucho más que airoso al enfrentarse a un concepto extraordinariamente lábil y escurridizo, caracterizado por una marcada ambigüedad semántica y sobre el que hay una profusa y, a veces, contradictoria bibliografía, un concepto al que ya se había acercado con anterioridad (Martínez Fernández, 1997a).

Si en aquel artículo J. E. Martínez logró reunir y valorar la intensidad de una trayectoria teórica y crítica de carácter diacrónico y aportar luz y claridad sobre la confusión y la ambigüedad que alcanzaban a diferentes conceptos teóricos (influencia, recepción, huella, interferencia, etc.) utilizados a menudo por la crítica de un modo indistinto, ahora, en el trabajo de 2001, consigue, con un acercamiento metodológico riguroso y un profundo conocimiento del estado de la cuestión, ordenar un ámbito demasiado complejo y difuso y sobre el que contamos, repito, con una bibliografía prácticamente inabarcable, una bibliografía que el autor del ensayo demuestra conocer y maneja con tino y autoridad. J. E. Martínez distingue entre dos visiones o aproximaciones no excluyentes al fenómeno intertextual: una visión general o global (a partir de la cual la intertextualidad se ve como una cualidad de todo texto, es decir, fuera de su ámbito el texto literario no sería perceptible) y otra visión estricta o restringida (la defendida por Genette o Claudio Guillén, entre otros) que la entiende como la presencia, explícita o implícita, de un texto en otros textos.

Se atiende, en primer lugar, a la conceptualización del texto y del texto literario, labores de delimitación previas e imprescindibles para abarcar posteriormente el alcance del propio concepto de intertextualidad. En este punto, relacionado con la tipología de los textos, las alusiones textuales y la dimensión específicamente comunicativa, aunque demostrando una considerable independencia crítica, J. E. Martínez se muestra cercano a planteamientos procedentes de la semiótica y la linguiística del texto. Pero, como él mismo se encarga de recordar, su interés se centra en la intertextualidad literaria y es ahí donde surge la labilidad del concepto y, por lo tanto, la dificultad a la hora de acotarlo, se resalta su origen en el dialogismo bajtiniano y se supera ampliamente el alcance de conceptos 
anteriores (fuentes, influencias, huellas, etc.). Como demuestra a lo largo de todo el estudio, la operatividad del concepto queda plasmada al aplicarse a la poesía social y a la poesía novísima, dos momentos muy diferentes y contrastados en el discurrir poético contemporáneo y en los que «los mecanismos intertextuales operan con diferentes funciones, objetivos y significación» (Martínez Fernández, 2001: 198). Se ocupa, al mismo tiempo, de otras nociones y categorías relacionadas intensamente con el tema principal del ensayo: el intertexto del lector, la intratextualidad, la intertextualidad exoliteraria. En fin, más allá de préstamos, ecos, huellas, citas, alusiones y otras muchas señales que nos dan cuenta de que la literatura universal respira un mismo aire de familia, la solvente y documentadísima investigación de J. E. Martínez nos coloca en la pista adecuada para entender que la intertextualidad, en su concepción global, «afecta a códigos, estructuras, arquetipos, a los procesos de emisión y recepción de textos...; pero, en cualquier caso, es un ámbito cuya exploración sigue manifestando su fecundidad teórico-crítica» (Martínez Fernández, 2001: 12).

Con el título de En la luz respirada se reunieron tres obras del poeta, narrador, ensayista y traductor Antonio Colinas: Sepulcro en Tarquinia (1975), Noche más allá de la noche (1983) y Libro de la mansedumbre (1997), tres libros pertenecientes a diferentes etapas que, a juicio del responsable de la edición, J. E. Martínez, acaso sean los más emblemáticos de su extensa producción poética, tres volúmenes que ejemplifican muy bien esa diversidad de voces y registros expresivos que encontramos en esta poesía, a veces marcadamente telúrica, otras neorromántica, en ocasiones tocada por un culturalismo contenido y en absoluto gratuito; una poesía que discurrió luego por senderos por donde transitan ciertas corrientes de la mística y el pensamiento oriental y que avanzó más tarde hacia un tipo de escritura más desnuda, menos encorsetada, desprovista de artificios innecesarios y al mismo tiempo más comprometida con la defensa de valores ecológicos. La «Introducción« que precede a los poemas, desarrollada a lo largo de ciento cuarenta y siete páginas, es un modelo de rigor filológico y análisis crítico que demuestra, muy a las claras, que José Enrique Martínez es un finísimo lector de poesía y un excelente conocedor del universo imaginario, la simbología, las derivas temáticas y los recursos expresivos y estilísticos que atraviesan la obra poética estudiada. Sin duda, nos encontramos ante un trabajo impecable, imprescindible para conocer y valorar esta escritura y, al mismo tiempo, muy adecuado para afrontar el análisis y la interpretación de temas y símbolos por los que ha transitado cierta poesía contemporánea. Más allá del tópico — repetido, a veces de manera injustificada, hasta casi la saciedad - sobre la confluencia de vida y poesía en un mismo lugar, J. E. Martínez defiende y argumenta con sólidos elementos de juicio la tesis de que Colinas es un poeta vital en el que los espacios vitales y los espacios poéticos acaban coincidiendo en un mismo y único espacio.

El lienzo de la página (La poesía y las otras artes) reúne, como he recordado más arriba, dieciséis textos, casi todos publicados con anterioridad, cuyo vínculo se encuentra en las relaciones que la poesía mantiene con otras artes. Se ocupa aquí de analizar textos de, entre otros, Luis Cernuda, Leopoldo Panero, Dionisio Ridruejo, Ángel González, Francisco Brines, José Bento, José María Álvarez, Tomás Hernández Molina, Luis Alberto de Cuenca y Lourdes Ortiz, de quien se analiza, y esta es la excepción (dado que todos los demás son textos poéticos), su novela Las manos de Velázquez. Más allá del 
alcance y la singularidad de todos y cada uno de los trabajos aquí reunidos, al margen de la vasta erudición desplegada, J. E. Martínez da muestra con inteligencia de las relaciones que, a lo largo de la historia, la poesía ha mantenido con otras disciplinas artísticas, especialmente, la pintura, aunque también con la música y, más recientemente, con la fotografía y el cine. Desde Simónides de Ceos, dichas relaciones han sido objeto de atención por parte de autores como Platón, Aristóteles, Horacio o Lessing, por citar solo unos pocos autores que se han ocupado de esta materia. A partir del tópico que habla de la pintura como poesía muda y de la poesía como pintura elocuente, J. E. Martínez, con extremado rigor y conocimiento de causa, rastrea el hilo del pensamiento teórico sobre la fructífera y enriquecedora relación entre las artes. Sin duda, en nuestro ámbito lingüístico, el autor de estos trabajos se presenta como una autoridad en el análisis de esas relaciones y, en este caso, actualiza el pensamiento sobre la interlocución entre la poesía y la pintura, incluye el estudio teórico de figuras retóricas como la écfrasis — con la que se evidencia o se pone ante los ojos un objeto ausente, en este caso, un cuadro pictórico - y la interpretación crítica de escritores y obras desde diferentes perspectivas comparadas y asentadas sobre la base común de la interacción artística, todo ello a partir de la convicción de que «la écfrasis ha evolucionado al tiempo que la poesía y la propia pintura han ido desde la imitación a la no referencialidad, en una parte al menos del arte actual a partir de las vanguardias» (Martínez Fernández, 2017: 17)

Dejo para el final un breve y muy personal texto, «Elogio de la poesía», que José Enrique Martínez escribió para un acto de celebración de la poesía que tuvo lugar el 13 de mayo de 2002 en León y en el que participaron los poetas Carmen Busmayor, Adolfo Alonso, José Luis Puerto y Luis Artigue. Allí, liberado de ataduras y servidumbres académicas, José Enrique pudo alzar su voz y expresarse «desde lo que tengo más a mano: mi propia experiencia con la poesía, mi convivencia emocional con ella, sin una sola mirada de desconfianza, sin una voz más alta que otra, sin una sola palabra de reproche»; allí, y en esas circunstancias, pudo compartir con su auditorio «el testimonio de un fervor». En ese texto, labrado con palabras lúcidas y penetrantes que dicta el corazón, José Enrique dio cuenta de su particular y emocionante viaje de iniciación por «el bosque de la poesía» y de cómo, a los catorce años y de la mano de Bécquer, «la poesía estalló en mí como una explosión» (Martínez Fernández, 2002: 12), abriendo en su alma «una puerta de luz inextinguible». Así, al recordar ese momento único, que se percibe desde la memoria en cierto modo como un acontecimiento, José Enrique no se ve a sí mismo como un elegido o tocado por los dioses sino que se sabe indistinto y cómplice junto a tantos y tantos otros adolescentes que un día «chocaron o chocarán con un verso como un momentáneo resplandor en los ojos, como un relámpago que alumbra un instante de eternidad» (Martínez Fernández, 2002: 13).

En ese texto, que puede muy bien leerse como un ensayo de poética personal, José Enrique alude a la inefabilidad de la revelación poética y al proceso según el cual, cada uno de nosotros, construimos nuestra particular tradición poética y cómo, al mismo tiempo, esa tradición nos configura de una u otra manera. En su caso, momentos insoslayables y radicales en esa búsqueda poética personal están asociados a Charles Baudelaire, Antonio Machado, Juan Ramón Jiménez, Salvatore Quasimodo y Luis 
Cernuda (cuya poesía pudo leer en la cuarta edición de La realidad y el deseo publicada por la editorial mexicana Tezontle en 1964). Años más tarde (como asimismo había hecho con la poesía de Bécquer), y al margen de sus aproximaciones críticas, José Enrique plasmaría en un poema lo que supuso para él su experiencia como lector de la poesía cernudiana: «Una pacífica mirada acoge el mundo: / la realidad y los fantasmas del deseo, / el vacío de un sueño contra el alba» (Martínez Fernández, 2002: 16), unos versos que demuestran que, junto al inteligente teórico y crítico literario que hay en él, camina un contenido, discreto y riguroso poeta capaz, entre otras muchas cosas, de comprender las contradicciones que habitan en la poesía, incluida su mala conciencia, y de intuir que «el que se siente habitado por la poesía no es más insolidario; algo me dice que en cada verso del poeta está el hombre en su totalidad. La poesía no redimirá al hombre del dolor, pero acaso palie sus angustias, acaso le dé fuerza para seguir viviendo, acaso acuda en cada ocasión como un deslumbramiento imprevisto en cuya esperanza de reiteración nos haga sobrevivir» (Martínez Fernández, 2002: 20-21). Sí, sobrevivir con la poesía, a la espera, con esperanza, de un acontecimiento inminente, como soñara Paul Celan, un mundo donde sea de nuevo posible conversar, dialogar, generar tiempos y escenarios sobre la base de modelos entrecruzados y diferentes, donde la palabra deje de actuar al dictado de un pensamiento limitado y constreñido y recobre ese aliento desestabilizador, rebelde y solidario con el que recrear el mundo, acciones y proyectos que, estoy convencido, han ocupado siempre un lugar relevante en el imaginario de José Enrique Martínez.

\section{Bibliografía}

MARTínez FernÁNDEZ, J. E. ed. (1989): Antología de poesía española (1939-1975). Madrid, Castalia.

- (1996): El fragmentarismo poético contemporáneo (fundamentos teórico-críticos). León, Universidad de León.

_ ed. (1997): Antología de poesía española (1975-1995). Madrid, Castalia.

_ (1997a): «De la influencia literaria a la huella textual», Exemplaria, vol. I, 179-200.

- (2001): La intertextualidad literaria (Base teórica y práctica textual). Madrid, Cátedra.

_ (2002): «Elogio de la poesía», en J. E. Martínez, C. Busmayor, A. Alonso, J. L. Puerto y L. Artigue, Elogio de la poesía. León, Diputación de León, 9-21.

- (2004): «Introducción», en A. Colinas, En la luz respirada, ed. de J. E. Martínez Fernández.

Madrid, Cátedra, col. Letras Hispánicas, 11-147.

(2005): Grupo Cántico de Córdoba. Comentario de poemas. Madrid, Arco Libros.

- (2017): El lienzo de la página (La poesía y las otras artes). León, Universidad de León. 